\title{
Response to Factors Affecting Resident Satisfaction in Continuity Clinic
}

\author{
Amalia J. Lyons, $M D^{\top}$, Susan Davids, $M D, M P H^{2}$, and Kathlyn E. Fletcher, MD, $M A^{2}$ \\ 'Department of Internal Medicine, Medical College of Wisconsin, Milwaukee, WI, USA; ${ }^{2}$ Department of Internal Medicine, Clement J. Zablocki \\ VAMC and the Medical College of Wisconsin, Milwaukee, WI, USA.
}

$\mathrm{J}$ Gen Intern Med 34(8):1370

DOI: $10.1007 / \mathrm{s} 11606-019-04988-7$

(c) Society of General Internal Medicine (This is a U.S. government work and not under copyright protection in the U.S.; foreign copyright protection may apply) 2019

$\mathrm{D}$ ear Editors,

The August issue of JGIM contained a systematic review by Stepczynski et al. that examined factors linked to resident satisfaction with primary care clinic experience. ${ }^{1}$ Two factors we found interesting were $\mathrm{X}+\mathrm{Y}$ scheduling and having excellent clinic preceptors.

The ultimate goal of residency is to train competent physicians, ready for clinical practice in their chosen fields. As practicing physicians, professional life is often marked by moving between the sometimes competing spheres of clinical, administrative, educational, and research duties. Many practicing physicians (primary care and subspecialists) have a presence in both the inpatient and outpatient worlds. $\mathrm{X}+\mathrm{Y}$ systems have advantages, but there are also downsides that should be considered, even with respect to clinical experience. When residency programs move to an $\mathrm{X}+\mathrm{Y}$ system, they are purposefully separating the spheres in a resident's clinical career - outpatient vs. inpatient. In actual practice, there is no separation of spheres. On the clinical side, previous work suggests that many Internal Medicine residents feel underprepared for treating many common outpatient conditions, while Family Practice residents feel underprepared for treating inpatient conditions. ${ }^{2}$ Ultimately, bridging and balancing the inpatient and outpatient curricula and patient care experiences may better prepare residents to be attendings.

A qualitative study sheds additional light on how residents view primary care careers and the role that clinic mentors play. Long et al. ${ }^{3}$ interviewed residents in primary care tracks at three institutions. They described in poignant detail the sometimes insurmountable barriers to providing the kind of care

Published online April 22, 2019 that they had envisioned providing. Specifically, they described the significant unmet social and mental health needs of their patients and not having the resources to address them. This led to frustration in the present and worry about burnout in the future. A common theme between the Long and Stepczynski papers is the importance that high-quality mentoring/role modeling plays in inspiring residents to become primary care physicians. Interestingly, there is evidence that good role models are aware of the available clinic and social resources. ${ }^{4}$ Faculty role models may be "protective" in preventing residents from losing their interest in primary care.

The Stepczynski study brings us closer to understanding how to increase residents' interest in primary care as a career. Inspiring more residents to become primary care doctors is an important objective, and this study is a solid contribution toward our roadmap to accomplish it.

Sincerely,

Amalia Wegner, Susan Davids, Kathlyn E. Fletcher

Corresponding Author: Kathlyn E. Fletcher, MD, MA; Department of Internal Medicine, Clement J. Zablocki VAMC and the Medical College of Wisconsin, Milwaukee, WI, USA (e-mail: kfletche@mcw.edu).

\section{REFERENCES}

1. Stepczynski, J., Holt, S.R., Ellman, M.S. et al. Factors affecting resident satisfaction in continuity clinic - a systematic review. J Gen Intern Med (2018) 33: 1386-1393.

2. Wiest FC, Ferris TG, Gokhale M, Campbell EG, Weissman JS, Blumenthal D. Preparedness of internal medicine and family practice residents for treating common conditions. JAMA 2002;288(20):2609-14.

3. Long $\mathbf{T}$ et al. Why aren't more primary care residents going into primary care? A qualitative study. J Gen Intern Med 2016 Dec;31(12):1452-1459.

4. Sisson SD, Boonyasai R, Baker-Genaw K, Silverstein J. Continuity clinic satisfaction and valuation in residency training. $\mathrm{J}$ Gen Intern Med 2007:22(12):1704-10.

Publisher's Note Springer Nature remains neutral with regard to jurisdictional claims in published maps and institutional affiliations. 